\title{
Transmural cystoscopy with an ultra-slim basket for migrated stent removal after endosonography-guided hepatic cyst drainage
}

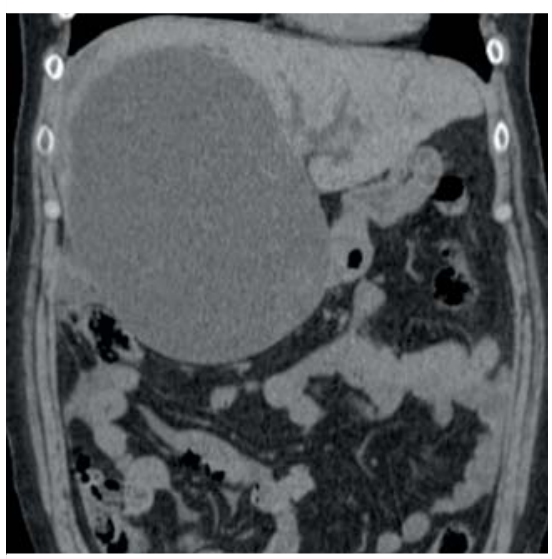

- Fig. 1 Computed tomography suggested cyst infection and cholestasis due to obstructed bile ducts.

A 55-year-old woman with a huge hepatic cyst was admitted because of abdominal pain, fever, and jaundice. Computed tomography suggested cyst infection and cholestasis due to obstructed bile ducts ( Fig.1). Because surgical or percutaneous interventions were refused, endoscopic ultrasound (EUS)-guided drainage with double-guidewire technique [1] was attempted via the stomach. However, the gastric end of a 7-Fr double-pigtail plastic stent was misplaced in the peritoneal cavity. Although a fully covered metal stent was deployed over another guidewire to catch the double-pigtail plastic stent in the cyst, the hepatic end of the fully covered metal stent was misplaced in the peritoneal cavity again ( $\mathbf{F i g} \mathbf{2}$ ). Following additional EUS-guided drainage with an external tube from the duodenal bulb, a standard endoscope was inserted into the peritoneal cavity through the fully covered metal stent, but the double-pigtail plastic stent could not be found ( Fig.3).

After 2 weeks of waiting for fistula maturation, removal of the double-pigtail plastic stent was attempted again using a duodenoscope (TJF-260V; Olympus Medical Systems, Tokyo, Japan). A guidewire was inserted into the cyst along the

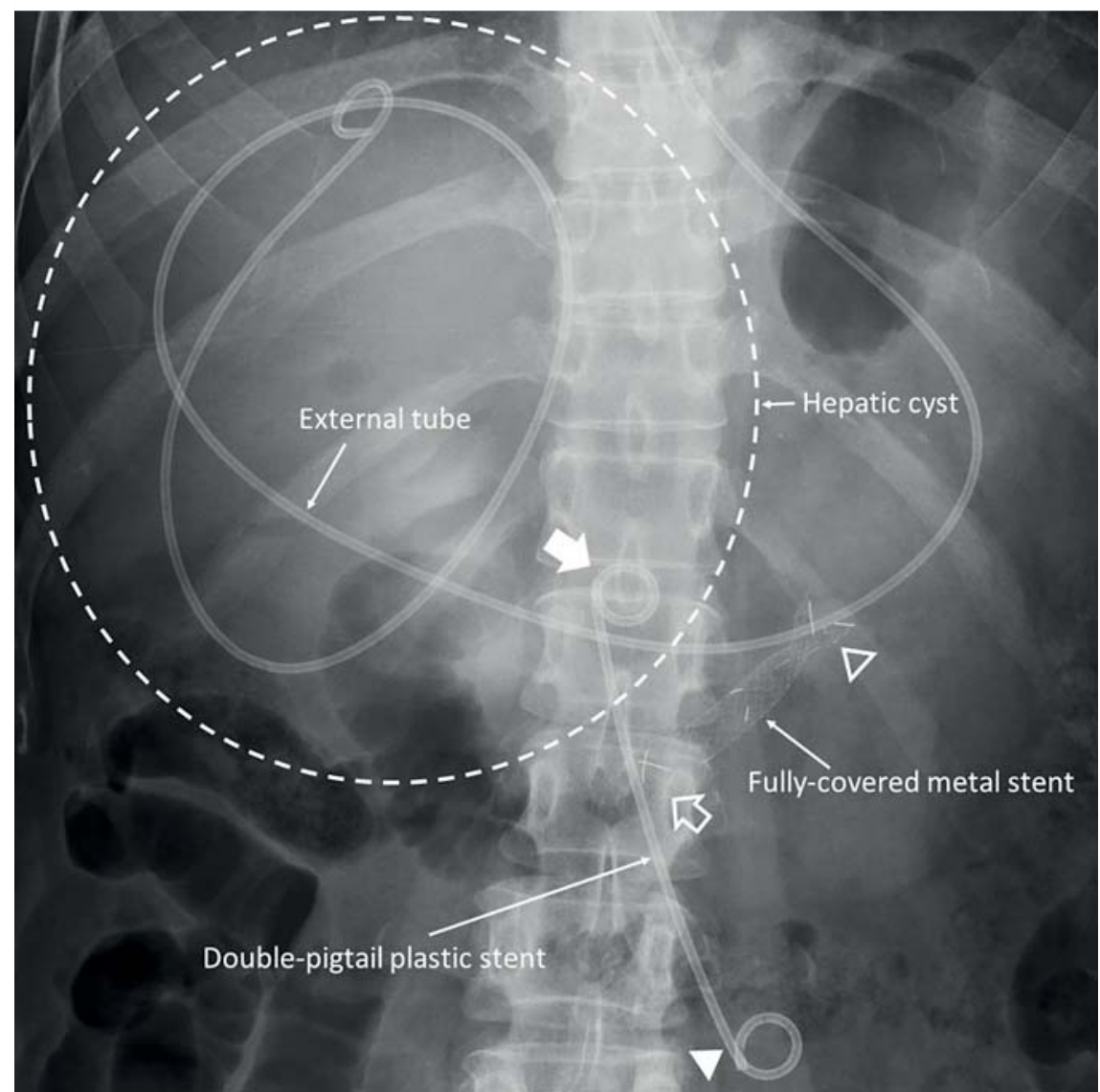

Fig. 2 An abdominal X-ray after endoscopic ultrasound-guided drainage. Double-pigtail plastic stent: the hepatic end (arrow) was in the cyst whereas the gastric end (arrowhead) was in the peritoneal cavity. Fully covered metal stent: the gastric end (open arrowhead) was in the stomach whereas the hepatic end (open arrow) was in the peritoneal cavity.

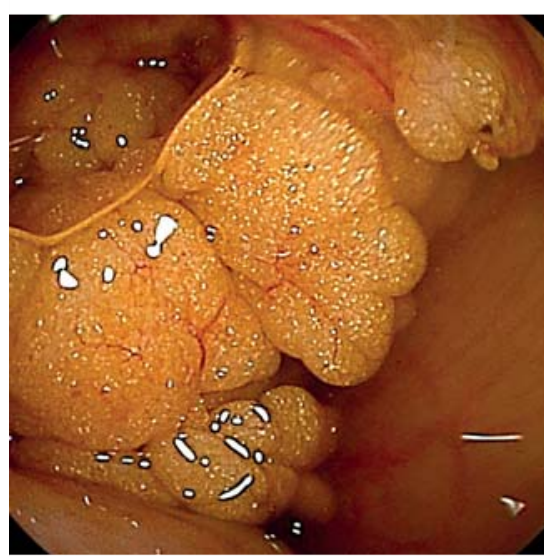

Fig. 3 An endoscopic view in the peritoneal cavity. The migrated plastic stent could not be found.

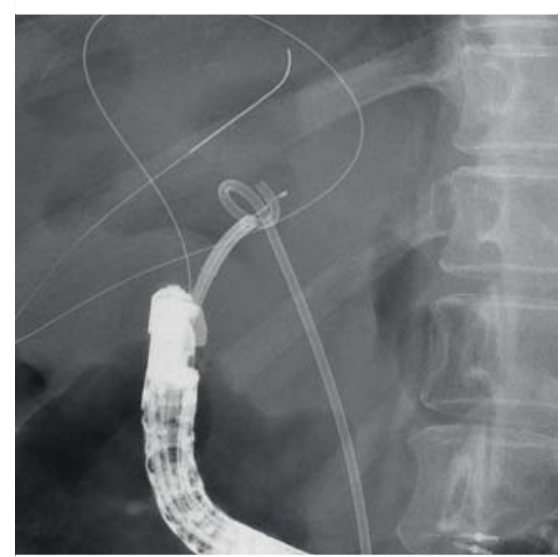

Fig. 4 A fluoroscopic view of grasping the plastic stent with a SpyBasket in the hepatic cyst. 


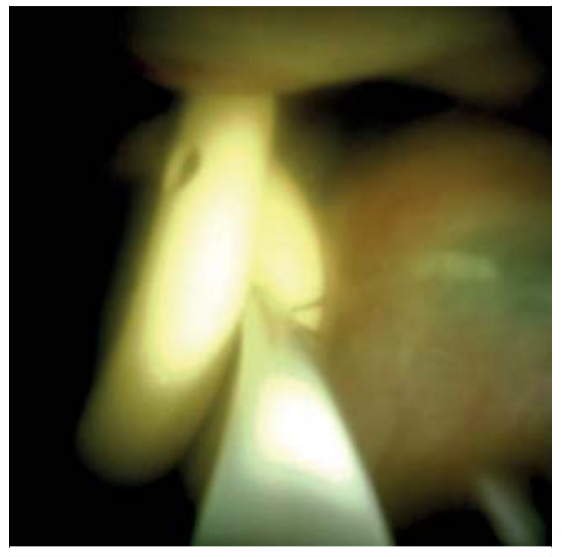

> Fig. 5 A SpyScope DS II view of grasping the plastic stent with a SpyBasket in the hepatic cyst.

external tube followed by fistula dilation with a balloon catheter. Grabbing the double-pigtail plastic stent was attempted with a wire-guided basket (TetraCatch V; Olympus Medical Systems) but failed. Thus, a SpyScope DS II (Boston Scientific, Natick, Massachusetts, USA) was inserted into the cyst, and the double-pigtail plastic stent was grasped by a dedicated forceps (SpyBite; Boston Scientific) under direct visualization but was lost during extraction owing to its weak grasping force. Finally, the double-pigtail plastic stent was caught tightly by a dedicated basket (SpyBasket; Boston Scientific) and successfully removed together with the SpyScope DS II ( $\triangleright$ Fig.4, $\triangleright$ Fig. 5, $\checkmark$ Video 1). At last, two plastic stents were placed.

Stent migration is one of the serious adverse events during EUS-guided drainage of abdominal fluid collections [2]. The application of a SpyBasket through a SpyScope DS II might be a useful option for removal of a migrated stent.

Endoscopy_UCTN_Code_CPL_1AK_2AG

\section{Competing interests}

The authors declare that they have no conflict of interest.

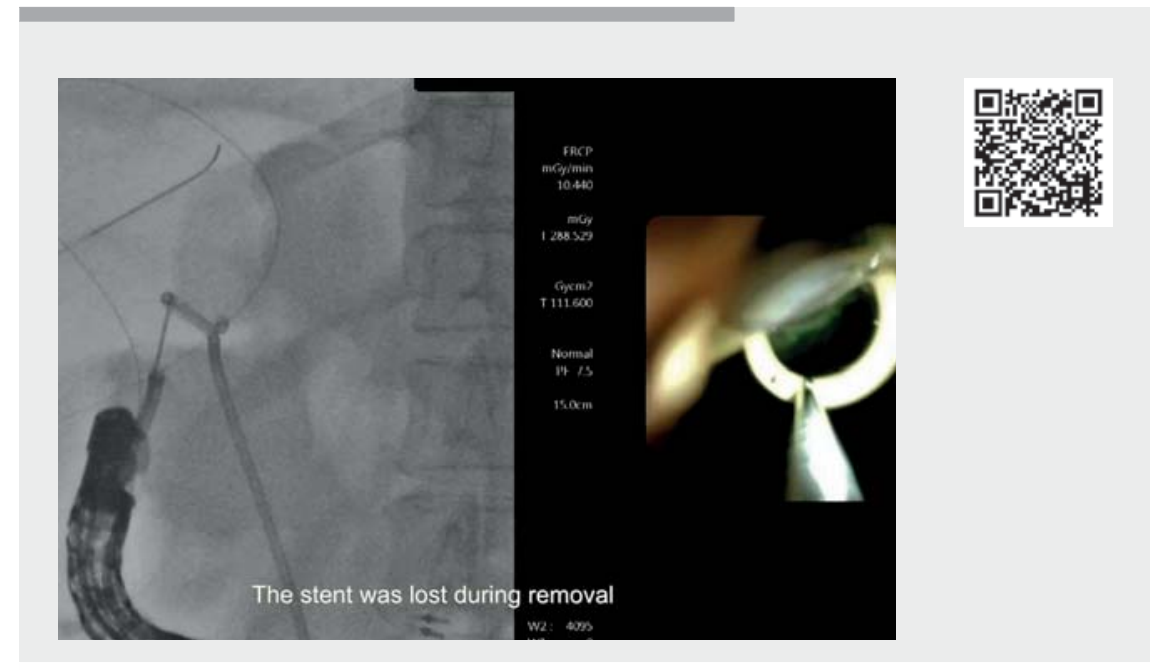

Video 1 Transmural cystoscopy with a SpyScope DS II for migrated stent removal after endosonography-guided hepatic cyst drainage using an ultra-slim basket.

The authors

Saburo Matsubara' ${ }^{\complement}$, Takayuki Tanaka, Keito Nakagawa, Kentaro Suda, Takeshi Otsuka, Masashi Oka, Sumiko Nagoshi

Department of Gastroenterology and

Hepatology, Saitama Medical Center, Saitama

Medical University, Saitama, Japan

\section{Corresponding author}

\section{Saburo Matsubara, MD}

Department of Gastroenterology and Hepatology, Saitama Medical Center, Saitama Medical University, 1981, Kamoda, Kawagoe-shi, Saitama 350-8550, Japan Fax: +81-49-226-5284

saburom@saitama-med.ac.jp

\section{References}

[1] Nakai Y, Oyama H, Kanai S et al. Double guidewire technique using an uneven double lumen catheter for endoscopic ultrasound-guided interventions. Dig Dis Sci 2020. doi:10.1007/s10620-020-06345-9

[2] Ryozawa S, Fujita N, Irisawa A et al. Current status of interventional endoscopic ultrasound. Dig Endosc 2017; 29: 559-566. doi:10.1111/den. 12872
Bibliography

Endoscopy 2022; 54: E220-E221

DOI 10.1055/a-1488-6332

ISSN 0013-726X

published online 31.5 .2021

(c) 2021. Thieme. All rights reserved.

Georg Thieme Verlag KG, Rüdigerstraße 14,

70469 Stuttgart, Germany

\section{ENDOSCOPY E-VIDEOS}

https://eref.thieme.de/e-videos

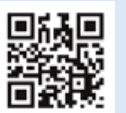

Endoscopy E-Videos is an open access online section, reporting on interesting cases and new techniques in gastroenterological endoscopy. All papers include a high quality video and all contributions are freely accessible online. Processing charges apply (currently EUR 375), discounts and wavers acc. to HINARI are available.

This section has its own submission website at

https://mc.manuscriptcentral.com/e-videos 